\title{
Trabalho adolescente: a experiência de uma ocupação regular
}

\author{
Régia Cristina Oliveira \\ Universidade Federal de São Paulo
}

O presente artigo tem o propósito de discutir questões referentes à experiência de trabalho regular e monitorado, voltado para adolescentes de baixa renda. Trata-se da reflexão de questões encontradas na pesquisa de doutorado relativas à participação de adolescentes das camadas populares em um programa da Empresa de Correios e Telégrafos de São Paulo denominado Adolescente Assistido. Dessa participação, questões importantes são destacadas neste artigo, dentre as quais: a associação entre pobreza e marginalidade na referência ao termo menor; as representações que uniformizam as categorias juventude, adolescência e pobreza e justificam práticas de intervenção; a experiência de trabalho na empresa e as normalizações moralizadoras; e as noções de empregabilidade definidas pela empresa. Destaca-se, ainda, a situação de inserção regular, uma vez que, quando pensamos em adolescentes de baixa renda, não apenas em nosso País, o trabalho precário e o desemprego logo lhes são associados, tanto por pesquisas nacionais quanto internacionais que investigam o tema e o ator social.

Palavras-chave: Juventude, Adolescência, Trabalho, Ocupação regular, Pobreza.

Teenage work: the experience of a regular occupation

The present text aims to discuss issues referring to the experience of regular and monitored work, directed to teenagers from low income backgrounds. It addresses issues which emerged from a doctorate research on the participation of teenagers from low classes in a program withheld by the Empresa de Correios e Telégrafos (Mail Services) of São Paulo, named The Assisted Teenager. In this article, important issues are highlighted, such as: the association between poverty and marginalization in the use of the term minor; the representations that level youth, adolescence and poverty categories and justifies intervention practices; the work experience at the company and the moralizing normalizations; and the notions of employability defined by the company. Furthermore, we point out the condition of a regular entry into the labor market, taking into account that not only in Brazil, but in other countries as well, precarious jobs and unemployment tend to be associated to teenagers from low income backgrounds, in national as international researches that study this thematic and social actor.

Keywords: Youth, Adolescence, Work, Regular occupation, Poverty.

\section{Introdução}

$\mathrm{O}$ artigo ora apresentado tem por objetivo trazer considerações levantadas em uma pesquisa ${ }^{1}$ a respeito do programa da Empresa de Correios e Telégrafos de São Paulo Adolescente Assistido, cujo propósito era a inserção regular, temporária e monitorada do trabalho de adolescentes de baixa renda.

Tratou-se de repensar essa categoria - adolescência - do ponto de vista sociológico, apreendendo, a partir do programa destinado a esses jovens, processos de socialização (Dubar, 2000) e de constituição social, a partir da experiência de trabalho e das mensagens, para além do trabalho, que ali recebiam. Buscou-se problematizar as categorias juventude, adolescência e vida adulta, no momento contemporâneo, a partir de uma experiência específica de trabalho na empresa.

Essa pesquisa, realizada entre os anos de 2002 a 2006, buscou apreender, por meio desse programa, o processo de constituição social do jovem adolescente das camadas populares, como

1 Trata-se de pesquisa de doutorado intitulada A constituição de si e a significação do mundo: uma análise sociológica sobre jovens trabalhadores. Essa pesquisa contou com o apoio financeiro da Fundação de Amparo à Pesquisa do Estado de São Paulo, FAPESP. 
trabalhador e como indivíduo, a partir das relações estabelecidas no local de trabalho e, também, nas esferas das quais participa, em especial a família e a escola, que dão sentido ao ato de trabalhar.

A escolha da Empresa de Correios e Telégrafos de São Paulo para a realização da referida pesquisa deveu-se à existência, em seu interior, desse programa voltado para adolescentes das camadas populares. Buscou-se avaliar em que medida a experiência de trabalho regular, monitorada e temporária estaria "penetrando" na vida dos jovens adolescentes - homens e mulheres -, fornecendo-lhes elementos para a constituição de si e do que os cerca, tendo em vista os propósitos declarados do programa, qual seja, de "formação" profissional e pessoal dos adolescentes.

Esse programa não está vinculado à Lei de Aprendizagem², sendo dela independente. Ele é resultado de uma iniciativa dos Correios, iniciada em 1994, com o objetivo de fornecer oportunidade de trabalho aos adolescentes de baixa renda, por um período determinado. Naquele ano, o programa anterior, Bom Menino ${ }^{3}$, deu lugar ao Adolescente Assistido. Neste programa, adolescentes, homens e mulheres, de dezesseis a dezessete anos e onze meses, eram contratados para aprender e executar atividades, nos setores administrativos e operacionais, no interior das unidades da Empresa de Correios e Telégrafos, em São Paulo e em outras regiões do Brasil, monitorados por um orientador/facilitador, em cada setor, que era o responsável por eles. Em tese, o monitoramento implicava acompanhar o desempenho do adolescente dentro da empresa e também na escola.

Segundo a proposta do programa, buscava-se fornecer ao adolescente uma orientação para e no trabalho, por meio de palestras e do monitoramento de funcionários. Essa orientação também seria feita por meio de conselhos que deveriam dizer respeito à vida desses jovens, ultrapassando, assim, os assuntos relacionados ao campo do trabalho.

Os adolescentes representavam mão-de-obra alternativa, juntamente com os portadores de deficiência física, que, desde o ano de 2001, também passaram a ser recebidos pelos Correios. Em 2003, o programa Adolescente Assistido estava passando por um processo de reestruturação, interrompendo novas contratações.

Desse modo, as observações e os apontamentos da pesquisa também acompanharam esse processo de transição.

Fruto de reformulações anteriores ao programa Adolescente Assistido, a abolição do termo menor foi central para o trabalho voltado para essa população. Todavia, ainda que estivesse, em tese, extinto, na prática, acompanhava o imaginário de muitos funcionários e as reclamações de quem se sentia alvo de "brincadeiras" a esse respeito.

Dentro da empresa, alguns adolescentes entrevistados referiram-se ao fato de determinados funcionários ainda chamá-los de menores, fato este que os desagradava bastante, dada a conotação pejorativa com que se percebia ser proferido, referindo-se à marginalidade.

A pobreza, o fato de serem "adolescentes assistidos", revelou representações referentes ao jovem e à família pobre, relacionadas à marginalidade, à violência e aos riscos de várias espécies.

Essas e outras considerações fazem parte das concepções e representações sobre os jovens adolescentes de baixa renda, as quais definem o papel da empresa em relação a esses indivíduos.

Um outro conjunto de questões apresentadas neste artigo diz respeito ao trabalho dentro da empresa até a saída para o mercado. Assim, são enfocados: o trabalho na empresa e os aspectos que infantilizam o adolescente como sujeito e como trabalhador, as normas existentes com vista à moralização do trabalhador assistido e, por fim, a preparação para o mercado de trabalho segundo a percepção da noção de empregabilidade.

\footnotetext{
2 Essa lei prevê a contratação obrigatória, por empresas de médio e grande porte, de adolescentes e jovens, na faixa etária dos quatorze aos vinte e quatro anos de idade.

3 O Programa Bom Menino integrava adolescentes que vinham do Círculo dos Amigos Patrulheiros de Santana, CAMPS. Eles executavam os mesmos trabalhos depois desempenhados pelos adolescentes assistidos, havendo ênfase na parte educacional. Com o passar do tempo, percebeu-se que aquela quantidade de jovens poderia ser expandida nacionalmente e decidiu-se fazer um programa que atendesse a todos os correios. Esse programa recebeu o nome de Programa do Adolescente Assistido.
} 
Todas essas questões são amarradas às percepções existentes dentro da empresa sobre esses jovens adolescentes, as quais circunscrevem expectativas relacionadas ao lugar e ao papel deles no mundo do trabalho e no meio social.

Desse modo, este artigo focaliza prioritariamente a empresa e os funcionários que respondem pelo programa destinado aos adolescentes, portanto, os olhares dos "outros" sobre os indivíduos assistidos. Para isso, serão apresentadas e discutidas falas de funcionários e trechos de manuais de conduta do e para o trabalho adolescente. Ao mesmo tempo e para ilustrar o incômodo gerado por determinadas considerações dentro da empresa a respeito dos adolescentes, será destacada e discutida a fala de uma das adolescentes participantes do programa.

Metodologicamente, dada a natureza interpretativa desta investigação, a abordagem utilizada na referente pesquisa foi qualitativa. Como técnicas metodológicas foram organizados grupos focais e realizadas entrevistas semiestruturadas com os sete adolescentes - três mulheres e quatro homens -, na faixa etária dos dezessete aos dezoito anos, dos oito participantes do programa Adolescente Assistido. Também foram entrevistados seis funcionários da empresa - uma mulher e cinco homens -, na faixa etária dos vinte e cinco aos vinte e sete anos de idade, ex-participantes desse programa, bem como pessoas ligadas ao departamento de pessoal que respondiam pela empresa e aquelas que estavam envolvidas com a coordenação do referido programa.

\section{Adolescência, juventude e trabalho: algumas distinções}

Nas ciências humanas, os estudos sobre juventude brasileira vêm adotando, como recorte de idade, a faixa etária dos quinze aos vinte e quatro anos de idade. Contemporaneamente, dadas as transformações nos processos de transição para a vida adulta, esse limite superior tem sido estendido, chegando, nos estudos europeus (Pais, 2001), a ultrapassar os trinta anos de idade.

Ainda que sensíveis a esse processo de extensão etária da condição juvenil, grande parte desses estudos não tomam a adolescência ${ }^{4}$ em específico, ainda que esteja ali pressuposta.

Esses dois termos - juventude e adolescência -, social e historicamente construídos, aparecem, muitas vezes, indiferenciados. Todavia, especialmente nas camadas populares, apresentam particularidades, dentre as quais a demarcação mais claramente colocada, na adolescência, da transição para a vida adulta, está associada à percepção de aquisição de responsabilidade (Guimarães, 2004; Oliveira, 2006), em especial, pela postura assumida diante do trabalho e, por meio dele, do auxílio ao grupo familiar.

A compreensão do limite de extensão etária da juventude advém da atual complexidade dos processos que, tradicionalmente, demarcavam a entrada na vida adulta, dentre os quais a saída da casa dos pais, a independência financeira, o término dos estudos e o casamento, fazendo com que a vivência e a definição da juventude, adolescência e vida adulta também se tornassem complexas.

Especialmente nas camadas populares (Oliveira, 2002, 2006) é possível identificar, entre os pesquisados, principalmente os homens, a percepção da adolescência como um momento mais claramente definido, diferente da juventude, vista como um valor que ultrapassa a condição etária (Pimenta, 2005; Oliveira, 2006), o que também justifica uma análise em específico sobre os diferentes significados da adolescência e da juventude em nossa sociedade.

A esse respeito, Sposito (1997) faz referência à quase ausência de pesquisas acadêmicas sobre os jovens adolescentes, na área das ciências humanas e sociais. A autora aponta a ampliação da visibilidade desse segmento social na esfera pública brasileira devido ao aumento da violência que lhe é associada.

4 Na presente pesquisa, em termos etários, e com base na Organização Internacional do Trabalho, considerou-se adolescentes os indivíduos que estavam compreendidos na faixa etária que se estende dos 15 aos 19 anos. Incorporando a compreensão da extensão da juventude também em nossa sociedade, a pesquisa contou com indivíduos com até vinte e sete anos de idade, avaliando, a posteriori, os significados da adolescência, juventude e vida adulta para cada um dos indivíduos pesquisados, segundo a percepção sobre si desenvolvida. 
Também informada pelo universo social ao qual pertence e pelas preocupações de sua época, dentre as quais a violência urbana juvenil, a medicina, importante campo de discursos (Foucault, 2006) e de intervenção sobre o corpo e os males que nos afetam (Adam \& Herzlich, 2001; Russo, 2006), congrega grande parte dos estudos desenvolvidos sobre a "adolescência".

Biologicamente, os adolescentes - jovens na faixa etária dos dez aos vinte anos incompletos, segundo a Organização Mundial da Saúde, OMS - são aí entendidos como indivíduos que, em ambos os sexos, apresentam um padrão diferente, marcado por um conjunto de transformações físicas, resultantes de "mecanismos" hormonais. Essas transformações dizem respeito à puberdade, fase de "amadurecimento sexual" (Calligaris, 2000). É na puberdade, uma construção médica (Rohden, 2001), que essas diferenças sexuais são reveladas e acabam por definir, desse ponto de vista, também os e as adolescentes.

Com base nessa perspectiva, a adolescência é pensada, grande parte das vezes, como uma das fases da vida; o processo de desenvolvimento do indivíduo compreendido a partir de sua passagem por etapas ordenadas da vida, do nascimento, infância, adolescência, vida adulta ao envelhecimento.

Sarti (2004) trabalha com essa questão, mostrando que essa compreensão diacrônica, evolucionista e linear do desenvolvimento infantil desconsidera o contexto sociocultural (Sarti, 2004) e, com ele, os sentidos, as diferenças e possibilidades de sua vivência. Singly (2000) também aborda essa questão, indagando-se a respeito da validade da utilização do termo "fase" para definir a adolescência nas sociedades contemporâneas, uma vez que, atualmente, as etapas fronteiriças da passagem à vida adulta são cada vez mais complexas.

Nas sociedades ocidentais, falar de adolescente trabalhador e de jovem trabalhador são coisas bem distintas, uma vez que, para esse âmbito, são trazidas as dificuldades impostas especialmente àqueles com menor escolaridade (Souza Martins, 1997), grande parte dos quais também com menor idade.

Como mencionam Druck et al. (2010), "a juventude brasileira em sua diversidade é trabalhadora" (p. 116). E, nas camadas populares, o trabalho começa cedo, na adolescência e, mesmo, na infância (Guimarães, 2005). Logo de início, esses jovens vivenciam formas precárias de inserção e vêm integrando o maior número entre o conjunto dos desempregados. Dados do Dieese, de 2005, mostram que naquele ano, em São Paulo, entre os jovens que estavam inseridos na força de trabalho, aproximadamente $32,6 \%$ estavam desempregados. Desse percentual, a maior parte era composta por mulheres, na faixa etária dos 16 aos 24 anos. Segundo a mesma fonte, o desemprego, que já é bastante preocupante no relativo à população jovem, recai particularmente sobre o grupo etário de 16 a 17 anos, adolescentes, segundo a Organização Internacional do Trabalho, OIT.

Mais recentemente, dados da OIT, de 2009, apresentados por Druck et al. (2010, p. 16), apontaram mudanças relacionadas à população jovem brasileira. Analisando os anos de 1991 e 2008, os dados mostram uma redução "daqueles que vivem do trabalho" ${ }^{\text {. }}$. Uma das razões encontradas refere-se "ao aumento da proporção de estudantes no grupo etário de 15 a 19 anos (...)", que passaram de 31,1\% em 1992 para 47,9\% em 2008.

No entanto, se analisarmos a situação dos jovens adolescentes das camadas populares, a realidade é diversa, uma vez que, comumente, há, já nesse período da vida, uma procura de conjugação do trabalho com o estudo (Oliveira, 2002), de formas de ocupação que lhes garantam algum rendimento, tanto para o consumo próprio quanto familiar. $\mathrm{Na}$ faixa etária assinalada, essa procura, em geral, resulta em formas precárias de inserção.

Inúmeros são os estudos que assinalam as dificuldades de inserção dos jovens no mercado de trabalho, analisando as elevadas taxas de desemprego - $46 \%$ da população desempregada, segundo dados da OIT - e de informalidade nesse segmento populacional (Druck et al., 2010). Essas dificuldades são ainda maiores para aqueles na faixa etária dos quinze aos dezessete anos, que ainda não têm idade adequada para o ingresso no mercado de trabalho, mas que buscam uma inserção, respondendo a expectativas no interior da família, dela fazendo parte, segundo um conjunto de obrigações recíprocas (Sarti, 1996), o trabalho remunerado dos filhos.

Como aponta Montali (2000, p. 42), "os componentes das famílias que estão sendo mais afetados ao acesso a empregos de qualidade são os jovens e os muito jovens", especialmente os menores

5 "Em 2008, aqueles que 'vivem-do-trabalho' representavam 53,3\% do total, uma redução de 5,9\% em relação a 1992" (Druck, 2010, p. 116). 
de dezoito anos, evidenciando, analisa a autora, a precariedade de inserção do adolescente, de ambos os sexos, no mercado de trabalho.

Assim, no mercado de trabalho, os obstáculos colocados aos jovens, aqui incluindo a faixa etária que se estende aos vinte e quatro anos, segundo a OIT, são potencializados quando referidos aos mais jovens, os adolescentes. Além da nova precarização social do trabalho (Duck et al., 2010) que a todos atinge, instituindo a instabilidade, a fragilidade dos vínculos e a insegurança permanente, os adolescentes que procuram trabalho vivenciam o acirramento dessas condições, contabilizando os maiores índices de desemprego entre a população jovem.

Por outro lado, para aqueles um pouco mais velhos, que estão saindo ou já saíram da adolescência, há a possibilidade de serem incorporados em espaços de trabalho nos quais há valorização da ausência de experiência anterior e da ausência dos "vícios" de trabalho. Trata-se da ideia atual de "formação" do(a) trabalhador(a) da maneira que o empregador considera mais apropriada (Oliveira, 2006). Esse conceito acompanha a valorização da juventude (Peralva, 1997), do "novo", no momento contemporâneo.

Diferente do período da adolescência, vivido e pensado como um momento mais claramente demarcado da vida dos indivíduos, articulado às transformações corporais e seus diferentes significados para ambos os sexos, a juventude é cada vez mais compreendida como um valor a ser cultivado, também em decorrência do seu prolongamento. Como questiona Souza Martins (1997), até quando vai a juventude? Qual o seu limite? Disso decorrem as indagações concernentes às implicações, também para os outros momentos da vida, dessa extensão.

Tomada como um valor que a relaciona à disposição e à alegria (Barbieri, 2008; Oliveira, 2001, 2006), a juventude também é valorizada no mercado de trabalho (Augusto, 2005; Oliveira, 2006), quando relacionada à capacidade inovadora, traço que a distingue e de fundamental importância "num mundo em constante transformação", salienta Augusto (2005).

Todavia, se a juventude expressa a ambivalência, ser sério, mas imaturo, ser audacioso, mas inexperiente, impulsivo, mas indeciso (Augusto, 2005), é especialmente na adolescência, ainda que com variações de recortes etários, que os qualificativos negativos são mais exaltados, atrelados à ideia de risco e da necessidade de ocupação (Sposito \& Corrochano, 2005).

Com base nesses argumentos, muitos programas são desenvolvidos, em especial, para esse segmento juvenil, exprimindo "parte das representações normativas correntes sobre a idade (...)" e sobre os atores aí considerados e construídos socialmente (Sposito \& Carrano, 2003, p. 18).

\section{Concepções sobre a adolescência de baixa renda: riscos e vulnerabilidade}

Contemporaneamente, circulam noções sobre adolescência que as associa à noção de crise (Matheus, 2002), desordem e irresponsabilidade; como problema social, que merece atenção e deve procurar ser solucionado. O risco generalizado (especialmente, o risco de gravidez precoce, de contrair Aids, de entrar na marginalidade, de usar drogas e de não ser inserido no mercado de trabalho) tem definido e circunscrito negativamente essa fase da vida, orientando a elaboração de programas e ações políticas (Sposito \& Carrano, 2003).

Sinalizando também a preocupação com a entrada de jovens e adolescentes na marginalidade e relacionando a ocupação - nas situações de trabalho, escola, lazer, cultura e arte - com a diminuição da sua vulnerabilidade a esse meio, o Ministério do Planejamento, Orçamento e Gestão apresentou um relatório - Orientações estratégicas de Governo do Plano Plurianual 2004-2007 - com diretrizes básicas ${ }^{6}$,

6 Sposito e Corrochano (2005) fazem referência ao reconhecimento do atual governo federal sobre a importância do tema juventude expresso por um conjunto de iniciativas, como: o Programa Primeiro Emprego, o Programa Pró-Jovem, a criação da Secretaria Nacional de Jovens e do Conselho nacional da Juventude. Todavia, alertam, essas iniciativas não configuram, necessariamente, "mudanças significativas no interior de uma agenda pública" que tenha a juventude e seus direitos como tema. Há uma série de conflitos em torno das ações voltadas para os jovens, quer seja pela disputa de recursos escassos, destinados às 
designadas por desafios que deveriam ser enfrentados no decorrer do período assinalado. No pacote de desafios 7, estão as diretrizes relacionadas às crianças, aos adolescentes e aos jovens que têm como objetivo "promover a redução da vulnerabilidade das crianças e dos adolescentes em relação à marginalidade e ao crime". Para tanto, algumas orientações são arroladas, dentre as quais podem-se destacar: a "priorização da arte, cultura, esporte e lazer na formulação das políticas voltadas a retirar crianças e adolescentes na marginalidade"; o "estabelecimento de políticas de valorização do primeiro emprego e ocupação" e a "priorização da oferta de qualificações e ocupação aos jovens que estejam entrando no mercado de trabalho".

As medidas propostas expressam a preocupação existente em nossa sociedade em relação aos jovens e adolescentes considerados vulneráveis e em situação de riscos, próprios dessa fase (violência, drogas, desemprego). A ocupação, feita especialmente pela via do trabalho, articula-se à ideia de que é necessário evitar que eles utilizem mal o seu tempo livre. O jovem e o adolescente são focados menos em sua positividade, no modo como experimentam e explicitam essas situações problemáticas, bem como outras possíveis questões que apresentem e as formas pelas quais pensam as mudanças, do que pela sua negatividade (Castro \& Abramovay, 2009), expressa pela falta, pela desordem que relaciona juventude a riscos de várias espécies.

Baseado nas concepções que enfatizam os riscos próprios da adolescência (Abramo, 1997), em especial da parcela pertencente às famílias de baixa renda, considerada mais vulnerável à entrada na marginalidade, o programa Adolescente Assistido configurou-se com o propósito de proporcionar uma ocupação responsável e adequada para esses indivíduos, fornecendo-lhes os valores necessários para a aquisição de hábitos e experiências desejáveis e afastando-os da marginalidade e das ruas.

Essa ocupação era exercida mediante atividade regular remunerada. Após cumprirem os prérequisitos $^{7}$ para o ingresso na empresa, os adolescentes eram contratados para trabalhar nos diferentes setores dos Correios. As atividades efetivadas dividiam-se em: administrativas de apoio (digitação, arquivo, protocolo, conferência e encaminhamento de documentos internos, atendimento telefônico, emissão de cópias xerox, fax e digitação em microcomputador e outras atividades auxiliares, definidas por cada chefe de cada seção) e operacionais (atendimento ao público, triagem de correspondência simples, carimbação, envelopamento, auxílio na transmissão e recepção de telegramas e outras, definidas por setor).

Dentro do programa, o adolescente era percebido como um indivíduo problemático, que precisava ser ajustado e auxiliado, ou assistido, para que, pelo trabalho, adquirisse hábitos adequados, que lhe propiciassem a convivência no meio social.

O manual do orientador ${ }^{8}$, importante instrumento do programa Adolescente Assistido, assim destacava seus principais objetivos: "promoção e desenvolvimento pessoal e profissional do adolescente assistido através da implementação de ações que assegurem a aquisição de hábitos, experiências e atitudes indispensáveis ao seu ajustamento no trabalho produtivo e na convivência social". Esse trecho sinaliza as concepções, representações (Lefebvre, 1980) ${ }^{9}$, olhares e, mais precisamente, o papel da empresa em relação ao jovem adolescente.

Em termos sociais, os adolescentes condensam preocupações derivadas de representações acerca dessa fase. Entretanto, não obstante as regularidades existentes, vivenciam suas experiências, informadas pelo seu contexto sociocultural, de forma singular. Todavia, grande parte dos projetos, políticas públicas e programas a eles destinados, em função de considerações biológicas/cronológicas, apreende-os como uma categoria homogênea, naturalizando a adolescência como período essencial para o crescimento do indivíduo e, segundo uma linha mais evolucionista, também essencial para o desenvolvimento social, na medida em que esse período da vida é visto como capaz de contribuir para a mudança mais ampla da sociedade e para a alteração do status quo (Lyra, 2002).

Apoiados nessa linha, que ressalta a ameaça que esses indivíduos representam, quando carentes de orientação apropriada para a aquisição de "hábitos e experiências indispensáveis ao seu ajustamento",

políticas sociais, quer seja em torno das “orientações que alimenta as ações” destinadas aos segmentos juvenis (pp. 3-4).

7 Eram pré requisitos: idade (ter entre 16 e 17 anos e onze meses), escolaridade (estar, pelo menos, na quinta série do ensino fundamental), renda familiar (a família do adolescente da comunidade deve contar com até três salários mínimos na sua renda total; quando filho de empregado, com renda familiar de até seis salários mínimos).

8 Documento contendo os objetivos e diretrizes do programa Adolescente Assistido.

9 A representação, que implica linguagem, refere-se ao que é "percebido" pelo indivíduo; à interpretação do vivido e da prática. 
muitos programas e políticas destinados aos adolescentes e aos jovens reforçam a ideia de que eles estão expostos a uma série de riscos próprios a essa fase de vida, que se manifestam pela violência ou mesmo pela dificuldade de identificação.

Com base nessas representações, busca-se evitar a entrada desses jovens adolescentes na marginalidade, nas situações de risco. Isso é mais visível quando falamos em jovens pobres. Nesse caso, parte-se da carência material dos indivíduos pobres para justificar as faltas existentes em seu comportamento e em sua formação moral.

A pobreza liga-se, então, à marginalidade (Castro, 1997). Os programas voltados para os jovens pobres, aqui incluídos aqueles considerados adolescentes, visam diminuir a possibilidade de que entrem nela ou, mesmo, aumentar as chances de tirá-los dali, mediante ações que os ocupem, tutelem e orientem, não apenas para o trabalho, mas também para a vida. Era o caso do programa apresentado.

Se, por um lado, vivemos um momento em que o gerenciamento de nossas vidas, nos tempos presente e futuro, cabe a nós mesmos (Melucci, 1997), a partir de escolhas que fazemos dentro das alternativas possíveis, crescendo nossa responsabilidade sobre nosso destino, representações a respeito do lugar dos jovens e adolescentes em cada espaço social (em especial, no trabalho e na escola) fundamentam ações e projetos destinados a eles, os quais visam ao seu direcionamento e à "promoção do seu desenvolvimento pessoal e profissional", como mencionava o programa.

Por trás dessas questões, havia uma noção de "dever ser" relacionada à imagem que o "outro" a empresa - elaborava sobre os adolescentes que entravam no programa, fazendo com que fossem estruturadas ações para transformá-los, segundo o que se acreditava que eles deveriam tornar-se - não apenas como trabalhadores, mas também como indivíduos - ao saírem da empresa. A ação da empresa, portanto, era daqueles que "sabiam" o que eram, o que queriam e no que se deveriam converter os adolescentes das camadas populares. Essa ação, especialmente no referente àquilo que os jovens deveriam se tornar e à conduta que deveriam assumir, revela o aspecto da norma, da prescrição, bem como das expectativas em torno do esperado nas ações voltadas a esse público (Sposito \& Corrochano, 2005).

De um modo geral, nessas ações, os jovens e adolescentes pobres são encarados como uma fonte potencial de problemas sociais (violência, drogas, Aids, gravidez, dentre outros). Como lembra Abramo (1997), a maior parte dos programas destinados aos jovens toma-os como problemas sobre os quais é necessário intervir para melhor integrá-los à ordem social, com o uso de estratégias de ressocialização e de capacitação profissional. Trata-se de fazer com que o jovem utilize o seu tempo livre de forma adequada, a partir de experiências consideradas apropriadas para essa fase da vida.

Outra aproximação feita entre pobreza e marginalidade referiu-se à utilização, por alguns funcionários, do termo menor para fazer referência aos adolescentes do programa.

Os adolescentes sentiam-se ofendidos ao serem identificados como "menores", visto que, antes de esse termo estar associado à faixa etária, em oposição aos trabalhadores jovens e adultos (não adolescentes), referia-se à contravenção, à marginalidade.

Particularmente na empresa em questão, a ideia da pobreza relacionada à negatividade reafirmava-se na ideologia do programa voltado para os adolescentes de baixa renda, que visava formar e educar os jovens para que estivessem "aptos" a participar da vida em sociedade. Por meio das brincadeiras com os adolescentes, os funcionários reafirmavam sua identidade de trabalhadores, não marginais, desqualificando os adolescentes assistidos. Os trabalhadores contratados, que passaram por seleção mediante concurso público, são como um grupo de indivíduos já estabelecidos (Elias, 1990) ${ }^{10}$, com status de funcionários da empresa. Os adolescentes eram vistos como indivíduos vindos de fora, que ficariam na empresa por um tempo determinado, não estando inseridos nas práticas de convivência estruturadas pelo tempo e pela questão da estabilidade, que configura simbolicamente as identidades dos outros funcionários e seu reconhecimento no coletivo da empresa.

10 Em estudo sobre uma comunidade inglesa, esse autor trabalha com a questão das relações que são desenvolvidas entre os indivíduos "antigos" e "novos", os últimos referindo-se àqueles que chegaram à comunidade, depois de um certo tempo e que, mesmo não apresentando diferenças de raça ou de classe social, são estigmatizados com "as características 'ruins' de sua porção 'pior' (....)". Ao mesmo tempo, o grupo antigo, os estabelecidos, tendem a se modelar "na minoria" de seus "melhores" membros, havendo entre eles grande coesão grupal dada pela antiguidade, pelo tempo de residência no lugar, o qual acompanha a consciência de grupo, bem como a adesão às suas normas e valores. 
Como analisa Schutz (1979), em todas as línguas, os termos têm diversas conotações. Todavia, além daqueles, encontrados e registrados no dicionário, há, em cada elemento da fala, outros significados secundários que têm sua origem no contexto ou ambiente social dentro do qual é usado; dependendo da ocasião, esses significados são acentuados. No caso em questão, o termo menor aparecia carregado de significados pejorativos, ainda que, a princípio, pudesse estar referido à menoridade etária. No entanto, no contexto em que era empregado - espaço da empresa, de legitimidade da condição de trabalhador - e da forma que era proferido - em meio a brincadeiras, que permitiam que verdadeiras intenções e opiniões fossem dissimuladas, mascaradas e escondidas, sobressaindo-se a descontração, para ambos os agentes da relação, adolescentes e funcionários -, ficavam claras a desqualificação e a associação a pobreza e marginalidade.

Uma das jovens entrevistadas expressa bem essa ideia ao dizer "eu não sou menor. Menor é assaltante". Ao fazer essa declaração e desabafo, a jovem está reivindicando a possibilidade de pertencer ao universo da pobreza, sem que isso a associe ao mundo da desordem. Está reivindicando a construção de uma autoimagem desvinculada da marginalidade, porque trabalha, estuda e tem uma família, como lembra em outra passagem da entrevista. Portanto, na visão da jovem, não apenas o fato de trabalhar possibilitava o seu distanciamento da desordem. Suas reivindicações referiam-se ao seu reconhecimento como estudante que também pertence a um grupo de apoio e proteção - a família -, participando, em ambas as esferas, de códigos de obrigações que atualizam e reafirmam seu lugar nesses campos simbolicamente constituídos como espaços sociais legítimos. Fazer parte desses universos, os espaços do trabalho, da escola e da família, significa autoafirmar-se como ser social detentor de direitos que estruturam, também simbolicamente, o seu lugar na e perante a sociedade, longe da marginalidade.

\section{O trabalho na empresa: da infantilização à "preparação" para o trabalho e para a vida}

Um dos elementos que apareceu de forma recorrente na entrevista de uma das funcionárias da empresa, que também respondia pelo programa voltado para os adolescentes, foi a utilização de diminutivos para fazer referência aos jovens. Por um lado, isso revelava a tentativa de aproximá-los da infância, por outro, e ao mesmo tempo, a consideração de que a essa quase "infância" cronológica estavam associados elementos "infantis", no sentido negativo do termo, dizendo respeito às carências simbólicas, associadas às carências materiais. Dessa forma, o "lanchinho", a "marmitinha", o "contratinho" de trabalho e o "curriculunzinho", que apareciam na fala, infantilizavam a imagem do trabalhador adolescente, estruturando o significado de sua presença na empresa segundo os olhares do "outro", justificando, nesse sentido, a ação protetora e formadora do programa sobre esses indivíduos.

Dada a forma com que foram colocados os diminutivos nas referências feitas aos adolescentes, essa ação protetora e formadora dos Correios sobre esses jovens parecia carregar consigo a ideia da assistência e, no limite, da filantropia, em detrimento da noção de direitos sociais. Era como se sua condição de trabalhador, infantilizada, os destituísse da posição de sujeitos de direitos - dentre os quais, o direito ao exercício do trabalho - e, nesse sentido, o trabalho realizado na empresa fosse considerado apenas um auxílio temporário aos indivíduos mais pobres; assim, no que se refere às atividades executadas, não resultasse na preocupação com uma real preparação desses jovens para o enfrentamento do mercado de trabalho, embora o discurso a respeito da preparação dos adolescentes buscasse ressaltar a importância de determinados atributos ali conquistados - como responsabilidade -, indispensáveis à conquista de um emprego.

Dentro da empresa, os adolescentes eram aproximados da infância, esta pensada como momento especial relacionado à aprendizagem, mas também à dispersão, ao descompromisso com o universo adulto. Assim, esses jovens eram vistos como indivíduos que precisavam aprender a se tornar responsáveis e disciplinados em relação às atividades que executavam, principalmente os homens. Nesse item, também apareceu a questão do gênero $\left(\right.$ Scott, 1995) ${ }^{11}$, aliada às expectativas e às representações

11 Entendendo por gênero as diferenças sexuais aceitas entre os sexos, em um dado tempo e lugar, as quais também expressam relações de poder. 
sobre o desempenho de papéis sociais masculino e feminino. Ao gênero feminino ligou-se, de forma "natural", o aspecto da docilidade e da delicadeza (Le Breton, 2006; Rohden, 2006) ${ }^{12}$.

Consideradas mais delicadas e disciplinadas, as jovens mulheres eram convocadas à participação nas palestras da empresa, assim como os jovens, ambos participantes do programa Adolescente Assistido. Essas palestras figuravam-se como um dos instrumentos de preparação dos jovens, tanto para o trabalho quanto para a vida.

Nas palestras, buscavam-se padronizar experiências de aprendizagem dos adolescentes no espaço da empresa, a partir de temas considerados comuns aos interesses deles, como drogas, empregabilidade e sexualidade ${ }^{13}$. A ideia era que conseguissem adquirir novos hábitos a partir das orientações recebidas. Todavia, os conhecimentos conquistados e as experiências vividas na realização dos trabalhos são apreendidos de forma singular. As respostas e reações às práticas na empresa conjugamse àquelas experimentadas fora do trabalho, em outras esferas da vida desses jovens. Estas não são, necessariamente, comuns; entretanto, esses jovens eram vistos e orientados homogeneamente, como adolescentes de baixa renda. Ao mesmo tempo, e aliado à condição social, eram pensados como sujeitos que, a priori, desconheciam o assunto a ser tratado ou não estavam adequadamente preparados para o seu enfrentamento.

\section{Normas e moralização: os jovens na empresa}

Um conjunto de normas definia o regime disciplinar, no caso do adolescente, baseado no Regulamento de Pessoal da Empresa de Correios e Telégrafos, ECT. O controle, tanto da chefia, dos orientadores, quanto do adolescente, do que deviam e do que não deviam fazer, delineava o perfil esperado de cada um e o papel que deviam desempenhar nas relações de trabalho assistido.

Junto às normas ligadas à assiduidade e à pontualidade, podem ser destacados alguns deveres, relacionados à higiene pessoal: "manter em ordem, limpo e arrumado o seu local de trabalho, zelando pela conservação de materiais confiados a sua guarda e utilização; apresentar-se sempre bem asseado, evitando o uso de trajes sujos, rasgados ou mal cuidados e de uniformes incompletos; obedecer e praticar os conselhos e regras de higiene e segurança no trabalho" ("Manual do Orientador"). Existia uma dimensão disciplinadora relacionada à higiene e à limpeza que, uma vez disseminada entre os indivíduos, os homogeneizava e, como era transmitida a todos, sem que houvesse privilégios, permitia à empresa a transmissão de um ideário "de harmonia social, de ausência de conflitos, de dignidade no espaço da produção” (Fleury, 1996).

O não cumprimento das normas relacionadas à higiene quebrava a ordem estabelecida, o pacto entre os indivíduos, fundamentado em sentimentos que, pensados compartilhados, estabeleciam o convívio nas relações de trabalho. A aparência adequada diz respeito a determinações elaboradas socialmente e relacionadas à dignidade e decência, mais do que à saúde. Argueiros (1999, p. 132), em seu estudo sobre o traje e o decoro, percebe a relação existente, principalmente para as camadas populares, entre os efeitos do traje e as relações sociais. Os indivíduos pobres, comenta a autora, talvez sejam mais sensíveis à importância do traje adequado nos diferentes espaços do meio social, em função da consciência de que "no mundo moderno a pessoa é o que pode fingir que é". Não se trata de cinismo, mas, antes, do reconhecimento de que não basta a cada um de nós acreditar ser isso ou aquilo. É necessário "mobilizar um equipamento de identificação, do qual a roupa é fundamental, para representar teatralmente para os outros (e para nós mesmos) o que imaginamos ser".

A questão do traje adequado e da higiene é especificamente importante no caso dos adolescentes. São esses os indivíduos que buscam constantemente a diferenciação, mediante os símbolos da juventude, expressos nas vestimentas ${ }^{14}$, no corte de cabelo, nos acessórios e nas gírias.

12 Segundo focos diferentes, esses autores tratam da questão de gênero, mostrando como algumas características atribuídas à mulher, embora social e historicamente construídas, aparecem naturalizadas no corpo, definindo lugares e hierarquias sociais.

13 Ministradas por funcionários da empresa ou por pessoas convidadas. As palestras, embora consideradas importantes pelos coordenadores do programa, não eram uma atividade sistemática, ocorrendo ocasionalmente.

14 Castro e Abramovay (2009) destacam esse aspecto, apresentando os seguintes dados para a pergunta feita, para jovens e 
O "rabo de cavalo" feito por alguns rapazes e o piercing são signos utilizados pelos jovens para, de um lado, evidenciar sua pertença ao universo juvenil e, de outro, estabelecer o distanciamento do universo adulto, em termos de identificação. Pais (2001) destaca que se associa à prática do consumismo a utilização de determinados signos, como as roupas da moda, pela juventude. A esse consumismo não estão ligados apenas os aspectos econômicos, mas também os sonhos, as imagens, as identidades. Na manipulação das fachadas visuais - como a utilização de piercing e de "rabo de cavalo" - os jovens desestabilizam convenções, permitindo a diferenciação e a originalidade. No caso desses adolescentes, podemos pensar que a utilização e a combinação desses signos representam também a manifestação do pertencimento desses indivíduos ao universo da juventude, mais do que a identificação de sua condição social de adolescente pobre. Busca-se, com isso, o afastamento do estigma - do adolescente pobre assistido - e dos elementos negativos a ele associados.

O uso obrigatório do traje adequado, da camiseta cinza - oferecida pelos Correios aos participantes do programa Adolescente Assistido - e do crachá de identificação, bem como das normas ligadas à higiene, impunham o controle e, ao mesmo tempo, a disciplina da empresa.

Outras normas disciplinadoras que merecem destaque e que contabilizavam a maior parte das prescrições referentes aos adolescentes estavam relacionadas à parte comportamental, referindo-se ao decoro e aos aspectos ligados à moral, podendo ser citados: a solidariedade, a cooperação, a discrição e o respeito.

Assim, cabia aos adolescentes "não faltar ao decoro, não usar linguagem e atitudes obscenas ou participar de brincadeiras levianas ou impróprias no recinto da empresa; tratar com urbanidade os chefes, instrutores e demais colegas de trabalho; guardar absoluta reserva sobre informações de que tenha conhecimento em razão da função que ocupa; manter espírito de cooperação e solidariedade, guardando respeito mútuo, evitando comportamento capaz de conturbar o ambiente e prejudicar o bom andamento do serviço; não se referir de modo depreciativo a quaisquer atos de administração e nem induzir outro colegas a não acatá-los; não se envolver em conflitos, não agredir física ou moralmente qualquer colega ou orientador; atuar na empresa visando o bem comum; não permitir a depreciação do nome da empresa levando a uma situação de intranquilidade e tensão"; por fim, "não fazer uso de bebidas alcoólicas ou de qualquer tóxico em serviço ou fora dele" ("Manual do Orientador").

Essas prescrições referiam-se a aspectos morais que deviam ser observados e cumpridos pelos adolescentes, por um lado, visando ao estabelecimento da ordem no espaço do trabalho, e, por outro, e relacionado ao anterior, enfraquecer o perigo potencial do risco ligado à marginalidade que perpassa as representações sobre os adolescentes de baixa renda. A moralização e a aquisição de hábitos e comportamentos desejáveis deveriam ser feitas no espaço do trabalho. Antes, porém, as normas prescritas para os jovens já definiam os valores, a visão da empresa sobre esses indivíduos e sobre as relações de trabalho nas quais estavam envolvidos.

Dentro do programa, buscava-se a moralização dos adolescentes, de acordo com o ideário da empresa. Tratava-se de "passar o recado", inculcando concepções idealizadas sobre o comportamento apropriado dos jovens, tanto na preparação para o trabalho quanto para a vida em sociedade. Os adolescentes eram socializados e moralizados no espaço do trabalho.

Não restritas ao espaço do trabalho, as exigências diziam respeito à vida e à formação do caráter do jovem, como adolescente de baixa renda, assistido. Essas prescrições, por vezes, eram claramente manifestadas como normas que não visavam apenas ao espaço da empresa, como é o caso do uso de bebida alcoólica ou de outro tóxico "em serviço ou fora dele".

Como destaca Fleury (1996), no espaço de trabalho, a proibição de bebida alcoólica tem como função manter o trabalhador distante de "hábitos morais que impeçam a canalização de suas forças única e exclusivamente para o trabalho" (p. 102). Também inscrita fora do espaço de trabalho, essa norma introduz a intervenção na vida privada do indivíduo. Como esclarece a autora, historicamente, a intervenção na vida privada dos trabalhadores por parte da organização, controlando como viviam, como gastavam seus salários, ligou-se ao exercício da moral para o trabalho, envolvendo, além da proibição do álcool, a proibição de uma vida sexual desregrada.

adolescentes, sobre o que melhor define o jovem dos dias de hoje: 37,7\% referiram-se ao itens relativos à linguagem e música; $34,7 \%$, o jeito de vestir e a aparência; 30,5\%, ser questionador/transgressor/ousado; $21,7 \%$, à consciência e responsabilidade; $23,7 \%$, a buscar adrenalina e correr riscos; $22,3 \%$, a insegurança pessoal e social; $20,4 \%$, a falta de perspectiva; $8,3 \%$, a instabilidade emocional e 6\%, ser egoísta. 
No caso dos adolescentes do programa, a intervenção da empresa em sua vida privada ocorria, em tese, em especial, por meio do monitoramento das relações familiares ${ }^{15}$, especialmente aquelas existentes entre pais e filhos. A empresa, por intermédio do programa, figurava-se como responsável pelo acompanhamento do adolescente, no que se referia não apenas à experiência de trabalho, como também de desenvolvimento pessoal. Eram quase crianças que precisavam ser orientadas no espaço do trabalho e, tanto quanto possível, em sua vida familiar e escolar.

Assim como os participantes do programa, as suas companhias deveriam ser examinadas. "A gente começou a desconfiar de um garoto que trabalhava aqui, se estava mexendo com drogas, porque vinha uma pessoa, com cara de marginal, procurar por ele”, comentou uma funcionária da empresa.

As más companhias também eram avaliadas de forma a "evitar a contaminação daqueles que não possuem 'valores desejáveis' e que podem eventualmente perverter o funcionário, colocando a perder todo o trabalho de moralização realizado anteriormente” (Fleury, 1996, p. 102). Havia o receio do contato com indivíduos que pudessem pôr a perder o trabalho de reeducação dos adolescentes. Esses indivíduos corporificavam a desordem, uma vez que infringiam normas de comportamento e de hábitos que eram considerados adequados, não apenas no espaço do trabalho.

A disciplina organiza os espaços (Foucault, 1988) nos quais as pessoas, homens e mulheres, são inseridas, a partir de lugares determinados, possibilitando o estabelecimento das presenças e das ausências. Dentro da empresa, a disciplina estabelecia os lugares, os horários e as atividades para os jovens. Os valores expressos nas normas situavam e classificavam o adolescente, segundo consideração que o deixava mais ou menos distante do imaginário e das expectativas criadas ao seu redor.

\section{Empregabilidade: a saída da empresa rumo ao mercado de trabalho}

Os aspectos relacionados às normas e à moralização são fundamentais para a compreensão de como era pensada a preparação para o mercado de trabalho. A percepção dessa preparação esteve relacionada à conquista pelo jovem de determinados atributos associados à empregabilidade.

A empregabilidade tem como pano de fundo o contexto das transformações por que passa a dinâmica do trabalho. As trajetórias anteriores dos trabalhadores, que determinam em muito suas trajetórias futuras (Castro, 1997), assinalam as chances, maiores ou menores, de o indivíduo conseguir um emprego ou mesmo de permanecer em seu cargo atual. Essas chances são traduzidas em empregabilidade. Todavia, a fala de uma funcionária que respondia pelo programa traz uma outra ideia: a responsabilização do indivíduo pelo sucesso ou fracasso na conquista de um emprego.

Empregabilidade está relacionada ao que esperam de você. Então, empregabilidade é um tema muito amplo. A gente fala pra ele: 'você vai sair daqui com dezessete anos e dez meses, então você vai procurar emprego. Como é que você vai procurar emprego, como é que você vai ser? Ah você vai cheio de piercing, camiseta justinha? Assim você não vai arrumar emprego. Você tem rabão de cavalo? Como é que você tem de estar vestido, postura, entonação de voz'. Falamos quais são os tipos de trabalho, as seleções para os adolescentes e como ele deve se portar.

Na fala, empregabilidade é atributo que se define pela ação do indivíduo, referindo-se às estratégias e comportamentos adequados na procura de um emprego. Todavia, a noção de empregabilidade deve aliar a ação dos indivíduos, as estratégias de emprego que definem suas biografias, construídas ao longo do tempo, às estratégias dos empregadores utilizadas para o preenchimento das vagas de emprego (Castro, 1997; Demazière, 1995). Falar em empregabilidade é ter em vista, portanto, as duas instâncias que dela fazem parte: os indivíduos que buscam uma colocação no mercado de trabalho - e suas ações, por um lado, e os empregadores, por outro ${ }^{16}$. A empregabilidade não é, portanto,

15 Todos os adolescentes moravam com os pais.

16 Nos termos de Demazière (1995), a empregabilidade é explicada por um componente intrínseco (resultante das trajetórias e características dos desempregados) e por outro extrínseco (que diz respeito ao desenvolvimento econômico e às transformações do mercado de trabalho). 
somente uma característica individual, mas depende também dos contextos estruturais, do desenvolvimento econômico e das dinâmicas do mercado de trabalho, nos quais as trajetórias individuais se desenvolvem.

Essa dupla consideração favorece a percepção das possibilidades de inserção ou de reinserção dos indivíduos no mercado, em especial dos jovens, dadas as transformações que ocorrem nos processos de trabalho, com crescente ocupação dos trabalhadores jovens e mulheres nas atividades não formais (Maruani, 2002).

Quando se associa o conceito apenas à dimensão individual, considera-se que o sucesso ou fracasso na busca de um emprego dependerá tão somente da capacidade que alguém tenha de se apresentar "empregável". Nesse sentido, o programa é pensado como um importante instrumento, capaz de ensinar aos jovens os passos necessários, inculcar-lhes valores e possibilitar-lhes a aquisição de novos hábitos, para que venham a ser bem-sucedidos futuramente, como trabalhadores "que respondem pelos seus atos". O resultado dessa intervenção é comentado sendo ressaltadas as histórias bem-sucedidas: "alguns voltam para visitar e contam que estão trabalhando. Na véspera do feriado, vieram dois portadores e três adolescentes", que apresentaram características adequadas e esperadas pelo mercado de trabalho, as quais foram adquiridas no programa.

Quais seriam as características que poderiam aumentar as chances do indivíduo? A princípio, poderíamos assinalar a escolaridade, os treinamentos adquiridos na empresa, a experiência de trabalho e os saberes relacionados a uma ocupação específica, que, reunidas, se referem à qualificação do trabalhador. No entanto, como demonstram Castro (1997) e Demazière (1995), a questão da empregabilidade não se restringe a isso. Características não formalizadas, como sexo, idade e, principalmente, condição racial, por vezes não reveladas abertamente, concorrem para aumentar ou diminuir as chances de inserção e reinserção dos indivíduos no universo profissional. Ser adolescente de baixa renda sinaliza, a princípio, um difícil caminho a percorrer, dadas também as representações existentes sobre esses indivíduos no mercado de trabalho.

Por outro lado, Demazière (1995) avalia a força de determinadas características, consideradas elementos de risco, como o pertencimento ao sexo feminino, a ausência de qualificação e a idade elevada do indivíduo, e percebe que são pouco eficazes para explicar os percursos dos desempregados de longa duração. Outros fatores, portanto, devem ser levantados, como a continuidade da trajetória profissional, a ausência de inatividade prolongada e o exercício de atividades ocasionais durante o período de desemprego, que favorecem a proteção contra o confinamento no desemprego prolongado.

No caso dos adolescentes que estavam ocupados, a questão colocada é a da possibilidade de aumento das chances de não entrada no desemprego, por ocasião do término do contrato. No momento em que estavam na empresa, como trabalhadores inseridos em um programa específico, a "preocupação" dos organizadores do programa era com sua formação, profissional e pessoal, adquirida com vista a uma boa inserção fora da empresa e a um bom desenvolvimento pessoal, longe da marginalidade, uma vez que tivessem incorporado os valores que lhes eram passados. O sucesso nesse intento dependeria do indivíduo. Como argumenta Frigotto (2004), essa tarefa está, cada vez mais, na responsabilidade de cada um. Contemporaneamente, analisa o autor, há uma noção generalizada de que é necessário que o indivíduo adquira um "pacote" de competências reconhecidas pelo mercado de trabalho como sendo adequadas ao novo cidadão que trabalha. $O$ que ocorre é a interiorização da ideia de que estar empregado depende de cada um, e não da estrutura social e das relações de poder. Essa noção faz intensificar a exploração do trabalho.

\section{Comentários finais}

Ao avaliar uma experiência de trabalho regular, voltada para adolescentes de baixa renda, ao menos três aspectos chamam a atenção: o ator social - adolescente de origem popular -, a possibilidade de inserção regular e a condição em que o trabalho era oferecido, ou seja, o aspecto do monitoramento e da formação para e no trabalho e, também, além dele. 
Esses aspectos configuraram-se como um terreno fértil para a compreensão da vida do adolescente de camadas populares em sua relação com o trabalho, em uma situação especial de inserção regular. Essa situação de trabalho também deve ser destacada, uma vez que, quando pensamos em adolescentes de baixa renda, não apenas em nosso País, o trabalho precário e o desemprego logo lhes são associados, seja pelas pesquisas nacionais e internacionais (Demaziére, 1995; Guimarães, 2005) que investigam o tema e o ator social, seja pela mídia falada e escrita que divulga dados a respeito desses jovens, trazendo um panorama da realidade atual.

Esse panorama também repercute associações entre pobreza e marginalidade. A falta de perspectivas dos jovens adolescentes das camadas populares faz emergir preocupações da sociedade civil com relação ao aumento da violência. Essas associações, por vezes, têm respaldo científico, dado pela dedicada investigação de acadêmicos, que também iluminam os caminhos de políticas públicas de juventude, ao menos, de seu debate. Mas, em outros casos, são resultado de representações que uniformizam as categorias juventude, adolescência e pobreza, simplificando questões que as envolvem e justificando práticas de intervenção baseadas em uma noção de "dever ser" que também impede considerar as possibilidades potenciais dos indivíduos, tanto dos jovens quanto de sua família (Sarti, 1999), de ultrapassarem suas vulnerabilidades, a partir de recursos próprios ou, ao menos, de serem coparticipantes nesse processo.

No caso apresentado, adolescentes pobres eram selecionados para um programa que visava, em tese, ao seu processo educacional. A educação no e para o trabalho, a educação para a vida, por meio das palestras, as normas e regulamentos, a moralização, a vigilância, o controle e a orientação compunham a tentativa de "construção" do adolescente assistido, segundo valores e representações sobre jovens de camadas populares, existentes dentro da empresa.

Embora o programa represente uma importante iniciativa da empresa de Correios, no referente à oferta de trabalho regular aos adolescentes de baixa renda, fundamental tanto do ponto de vista material quanto simbólico, pela existência da carteira de trabalho, ele traz em seu bojo concepções estigmatizantes, expressas por como concebe a adolescência das camadas populares, destacando-se a homogeneidade na consideração dos indivíduos ali representados, e a associação feita entre carência material e moral, definida pelo perigo potencial de entrada na marginalidade. De qualquer maneira, essa imagem projetada da adolescência desses estratos já é produto de uma construção social; de uma concepção generalizada, contemporaneamente, sobre esses indivíduos, reforçada pelos meios de comunicação de massa, o que revela a necessidade de quebra e de reconstrução dessa percepção para organização de programas, bem como de políticas públicas voltadas para esses jovens. Esse movimento pressupõe a escuta desses indivíduos, não apenas em referência àquilo que dizem ser, mas também àquilo que almejam conseguir, tanto no referente à ocupação pelo trabalho quanto a outras e novas formas legítimas de inserção social.

\section{Referências}

Abramo, H. W. (1997). Considerações sobre a tematização social da juventude no Brasil. Juventude e Contemporaneidade. Revista Brasileira de Educação, 5/6, 25-36

Adorno, S. (2000). Adolescência, crime e violência. In H. W. Abramo, M. V. Freitas \& M. P. Sposito (Orgs.), Juventude em debate (pp. 97-109). São Paulo: Cortez.

Adam, P. \& Herzlich, C. (2001) Sociologia da doença e da medicina. Bauru: Edusc.

Argueiros, G. H. (1999). O traje e o decoro. In J. S. Martins (Org.), Vergonha e decoro na vida cotidiana da metrópole (pp. 125-136). São Paulo: Hucitec.

Augusto, H. H. O. (2005) Retomada de um legado intelectual: Maria Alice Foracchi e a sociologia da juventude. Tempo Social, 7 (2).

Calligaris, C. (2000). A adolescência. São Paulo: Publifolha.

Castro, N. A., Cardoso, A. M. \& Caruso, L. (1997). Trajetórias ocupacionais, desemprego e empregabilidade: há algo de novo na agenda dos estudos sociais do trabalho no Brasil? Contemporaneidade e Educação, 1 (2), 7 23. 
Castro, M. G. \& Abramovay, M. (2009). Quebrando mitos. Juventude, participação e políticas. Perfil, percepções e recomendações dos participantes da $1^{\underline{a}}$ conferência nacional de políticas públicas para a juventude. Brasília: RITLA.

Degenne, A., Fournier, I. \& Marry Mounier, L. (1991). Les relations sociales au coeur du marche du travail. Sociétés Contemporaines, 5, 75-97.

Demaziere, D. (1995). La sociologie du chômage. Paris: PUF.

Dubar, C. (2000). La socialisation. Construction des identités sociales et professionelles. Paris: Armand Colin.

Druck, G., Oliveira, L. P. J. \& Jesus, S. C. S. (2010). Precarização social do trabalho no Brasil: o caso da vulnerabilidade dos jovens e dos sindicatos. In T. Braga, F. Vidal \& L. Neves (Orgs), Trabalho em questão (pp. 103-130). Salvador: SEI.

Elias, N. (1990). Os estabelecidos e os outsiders. Rio de Janeiro: Zahar.

Fleury, M. T. L. (1996). Cultura e poder nas organizações. São Paulo: Atlas.

Foucault, M. (1988). Vigiar e punir. Petrópolis: Vozes.

Foucault, M. (2006). História da sexualidade. A vontade de saber I. São Paulo: Graal.

Frigotto, G. (2004). Juventude, trabalho e educação no Brasil: perplexidades, desafios e perspectivas. In R. Novaes \& P. Vannuchi (Orgs.), Juventude e sociedade: trabalho, educação, cultura e participação (pp. 180-216). São Paulo: Perseu Abramo.

Guimarães, N. A. (2005). Trabalho: uma categoria-chave no imaginário juvenil? In H. W. Abramo \& P. P. M. Branco (Orgs.), Retratos da juventude brasileira: análise de uma pesquisa nacional (pp. 149-174). São Paulo: Perseu Abramo.

Le Breton, D. (2006). Sociologia do corpo. Petrópolis: Vozes.

Lefebvre, H. (1980). La présence et l'absence: contribution à la théorie des représentations. Bélgica: Castermann.

Lyra, J., Benedito, M., Nascimento, P., Galindo, D., Moraes, M. \& Pedroso, C. (2002). "A gente não pode fazer nada, só podemos decidir sabor de sorvete". Adolescentes: de sujeito de necessidades a um sujeito de direitos. Cadernos CEDE, 57 (22), 9-21.

Maruani, M. (2002). Travailleurs, travailleuses: qui sont les salarités pauvres? In Les mécomptes du chômage (pp. 79. 100). Paris: Bayard.

Matheus, T. C. (2002). Ideais na adolescência: falta (d)e perspectivas na virada do século. São Paulo: Fapesp.

Montali, L. (2000). Família e trabalho na reestruturação produtiva: ausência de políticas de emprego e deterioração das condições de vida. Revista Brasileira de Ciências Sociais, 15 (42), 41-75.

Melucci, A. (1997). Juventude, tempo e movimentos sociais. Revista Brasileira de Educação, 5/6, 5-14.

Oliveira. R. C. (2006). A constituição de si e a significação do mundo: uma análise sociológica sobre jovens trabalhadores. Tese de Doutorado, Departamento de Sociologia, Universidade de São Paulo, São Paulo.

Oliveira. R. C. (2001) Jovens trabalhadores: representações sobre o trabalho na contemporaneidade. Dissertação de mestrado, Departamento de Sociologia, Universidade de São Paulo, São Paulo.

Pais, J. M. (2001). Questões da infância e juventude na América Latina. In Seminário internacional sobre a criança e o jovem na América Latina (Comunicação pessoal). Marília.

Peralva, A. T. O. (1997). O jovem como modelo cultural. Revista Brasileira de Educação, 5/6, 15-24.

Pimenta, M. M. (2005). Trajetórias juvenis. Tese de Doutorado, Departamento de Sociologia, Universidade de São Paulo, São Paulo.

Rohden, F. (2001). Uma ciência da diferença: sexo e gênero na medicina da mulher. Rio de Janeiro: Fiocruz.

Russo, J. (2006). Do corpo-objeto ao corpo-pessoa: desnaturalização de um pressuposto médico. In A. N. Souza \& J. Pitanguy (Orgs,), Saúde, corpo e sociedade (pp. 183-194). Rio de Janeiro: UFRJ.

Sarti, C. A. (1996). A família como espelho: um estudo sobre a moral dos pobres. São Paulo: Autores Associados.

Sarti, C. A. (1999). Família e jovens no horizonte das ações. Revista Brasileira de Educação, 11, 99-109.

Sarti, C. A. (2004). O jovem na família: o outro necessário. In R. Novaes \& P. Vannuchi (Orgs.), Juventude e sociedade: trabalho, educação, cultura e participação (pp.115-129). São Paulo: Perseu Abramo.

Schutz, A. (1979). Fenomenologia e relações sociais. Rio de Janeiro: Zahar. 
Scott, T, J. (1995). Gênero: uma categoria útil de análise histórica. Revista Educação E̊ Realidade, 2 (20), 71-99.

Singly, F. (2000). Penser autrement la jeunesse. Lien Social et Politiques, 43, 9-23

Souza Martins, H. H. T. (1997). O Jovem no mercado de trabalho. Revista Brasileira de Educação, 5/6, 96-110.

Sposito, M. P. (1997). Estudos sobre juventude em educação. Revista Brasileira de Educação, 5/6, 37-52

Sposito, M. P. \& Corrochano, M. C. (2005). A face oculta dos programas de transferência de renda para jovens no Brasil. Tempo Social, 2 (17), 141-172.

Sposito, M. P. \& Carrano, P. C. R. (2003). Juventude e políticas públicas no Brasil. Revista Brasileira de Educação, 24, 16-39.

\section{Endereço para correspondência}

rcolira@yahoo.com.br

Recebido em: 04/12/2009

Revisado em: 21/10/2010

Aprovado em: 03/11/2010 